\title{
Estratégia para Especificação de Game Design a Partir da Produção Textual em Sala de Aula
}

\author{
Eduardo Henrique da Silva Aranha \\ Dep. de Matemática e Informática Aplicada - DIMAP \\ UFRN \\ Natal, RN, Brasil \\ eduardoaranha@dimap.ufrn.br
}

Um Relato da Experiência

\author{
Márcia Jacyntha Nunes Rodrigues Lucena \\ Dep. de Matemática e Informática Aplicada - DIMAP \\ UFRN \\ Natal, RN, Brasil \\ marciaj@dimap.ufrn.br
}

\author{
Gildene Lima de Souza Fernandes \\ Núcleo de Educação da Infância - NEI/CaP \\ UFRN \\ Natal, RN, Brasil \\ gilsouzafernandes@gmail.com
}

\begin{abstract}
Digital games are increasingly part of our daily lives and are also considered teaching and learning tools. However, its production and documentation is a very complex task that requires programming skills and knowledge of various areas. This has hampered the development of classroom games. On the other hand, enthusiastic teachers and students have ventured into this activity as a way of learning school content and developing computational thinking in a more fun and meaningful way. A strategy for creating games using natural language seems to be an alternative to adopting game-based learning, developing computer thinking and writing skills. In this context, this article reports an experience of specifying game design from textual production by students and teachers in the classroom.
\end{abstract}

\section{KEYWORDS}

Game Design, Produção Textual, Serious Game

\section{INTRODUÇÃO}

A presença cada vez mais forte das tecnologias digitais em nosso cotidiano tem facilitado o acesso ao conhecimento e a abertura de novas possibilidades educacionais. Algumas Escolas e Universidades têm adotado o uso dessas tecnologias, sobretudo a aprendizagem baseada em jogos, como forma de ajudar seus alunos a aprenderam de maneira mais significativa e desenvolverem as competências e habilidades relacionadas à tecnologia e à computação, sobretudo o pensamento computacional [5].
Educadores entusiastas também tem se interessado mais pelos jogos educacionais. Eles têm descoberto o potencial do uso dos jogos digitais em sala de aula [17] e sentem que podem impulsioná-los a aprenderem através do uso e criação dos seus próprios jogos $[14,12,16]$.

Para Marinho et. al. [11] é possível extrapolar o uso de jogos na educação. Seus estudos mostram que professores e alunos podem se envolver em projetos de produção de jogos na própria escola. Os resultados apontam excelentes ganhos na aprendizagem, desenvolvimento cognitivo, aumento da criatividade e autonomia dos alunos, sem falar que oportuniza conhecer um domínio específico computacional. Segundo Danielle et. al. [6] professores tornam suas aulas mais interessantes e significativas para os alunos que, motivados em desenvolver seu próprio jogo, aprendem os conteúdos de diversos componentes curriculares envolvidos no projeto, configurando-se como uma atividade interdisciplinar.

A produção de um jogo é iniciada na concepção da sua ideia e especificação de requisitos, chamado Game Design. A especificação do Game Design de um jogo é uma tarefa complexa, trabalhosa e ainda sem um padrão formal estabelecido pela comunidade de desenvolvedores de games. É um processo que envolve criatividade, imaginação, definição do funcionamento do jogo, documentação e comunicação. Os documentos de game design, por consequência, são muitas vezes difíceis de serem entendidos, faltam informações e são inconsistentes. Geralmente são apresentados na forma escrita e não fornecem clareza a pessoas inexperientes. Essa atividade, se não for bem executada, pode gerar imprecisão das informações, erros conceituais, dados 
mal coletados, fruto do mau entendimento que poderá dificultar a etapa de desenvolvimento do jogo.

Portanto, criar e documentar jogos exige conhecimentos específicos e uma curva de aprendizado significativa para não desenvolvedores o que pode ser um grande desafio tanto para professores como para alunos [15].

Algumas ferramentas que utilizam programação visual têm auxiliado professores e alunos a desenvolverem jogos digitais, como por exemplo e Aventura [16-7], Scratch [10], Alice [9-18] e A Hora do Código [19]. Porém, existe uma carência de metodologias específicas para o desenvolvimento de jogos educativos. Poucas são as iniciativas que propõem a especificação do game design de jogos por alunos e professores [8].

Em paralelo, os resultados de algumas pesquisas evidenciam dificuldades no desenvolvimento de habilidades de leitura e escrita para produção de textos. Historicamente, os resultados das avaliações da educação básica têm mostrado deficiência na aprendizagem da matemática e da língua portuguesa [13-4].

Observam-se pesquisas que apresentam soluções tecnológicas que priorizam a resolução dos problemas da matemática, porém na área de produção textual (língua portuguesa) poucas são apresentadas. Ou seja, existe uma lacuna em relação a estratégias que façam uso da tecnologia e que possam contribuir com a aprendizagem da língua portuguesa, sobretudo na produção textual. $[3,1,2]$.

Produzir jogos em sala de aula pode favorecer o desenvolvimento do pensamento computacional, pois ao produzilo o aluno pensa na resolução de uma problemática envolvida no jogo, sua decomposição, a construção de algoritmos para resolução desse problema e a identificação de características comuns entre os problemas e suas soluções. Além de favorecer o desenvolvimento de habilidades na área da língua portuguesa, também previstas na BNCC [4], mediante o uso da leitura e escrita para produção do game design dos jogos, tais como: planejar textos considerando a situação comunicativa, o suporte, a linguagem; compreender e produzir com autonomia textos instrucionais de regras do jogo.

Uma estratégia eficiente que suporte a elaboração do game design de jogos no contexto educacional mostra-se determinante $\mathrm{e}$ pode reduzir a barreira da adoção da aprendizagem baseada em jogos. Uma estratégia que possibilite a geração automática de artefatos de game design através de textos podem ser uma das saídas, principalmente para aqueles que têm pouco ou nenhum conhecimento técnico nessa área.

Portanto, criar jogos a partir da linguagem natural parece ser uma alternativa para solução desses desafios.

Neste contexto, este artigo relata uma experiência da especificação de game design a partir da produção textual por alunos e professores em sala de aula. Através de um estudo exploratório buscamos compreender o processo de especificação do game design de jogos digitais través da produção textual respondendo as seguintes questões: Quais as características que uma linguagem deve possuir para especificar game design de forma a viabilizar a geração de jogos de maneira automática? A estratégia proposta motiva a produção textual?

\section{FUNDAMENTAÇÃO TEÓRICA}

Essa seção apresenta os principais assuntos relacionados ao tema de pesquisa.

\subsection{Pensamento Computacional}

Atualmente muito se tem discutido sobre o desenvolvimento do pensamento computacional como uma das habilidades essenciais do mundo moderno. Essa necessidade é decorrente da rápida evolução tecnológica e sua inserção nas diversas áreas do conhecimento. É difícil imaginar uma sociedade sem computadores, dispositivos móveis e suas tecnologias. Assim, o conhecimento em computação deve constituir a formação básica do cidadão.

Originalmente Wing [36] conceitua pensamento computacional como uma forma de pensar e encontrar soluções para os problemas cotidianos utilizando para isso os fundamentos da computação e matemática. Segundo a autora, o pensamento computacional é uma habilidade básica, assim como ler, escrever, falar e realizar operações matemáticas.

Segundo Brackmann [37], "o pensamento computacional é uma distinta capacidade criativa, crítica e estratégica humana de saber utilizar os fundamentos da computação nas mais diversas áreas do conhecimento, com a finalidade de identificar e resolver problemas colaborativamente através de passos claros de tal forma que uma pessoa ou uma máquina possam executá-los eficazmente". É saber utilizar os conceitos da computação para resolução de problemas do nosso cotidiano.

Assim, como pioneiramente defende Wing [36], entendemos o pensamento computacional como uma habilidade para todos, não se constituindo como uma área do conhecimento restrita aos profissionais da computação.

Portanto, uma das estratégias de trabalhar o pensamento computacional em sala de aula é através da aprendizagem baseada em jogos cujo conceito será apresentado na seção seguinte.

\subsection{Aprendizagem Baseada em Jogos}

Os jogos educativos, sobretudo os digitais, podem ser considerados objetos de aprendizagem que, quando utilizados em sala de aula, permitem ao aluno vivenciar uma experiência imersiva e motivadora. Os jogos digitais, ao permitirem a simulação em ambientes virtuais, proporcionam momentos ricos de exploração de diversos conteúdos e desenvolvimento do pensamento computacional. Esse é um dos motivos que fazem dos jogos digitais educativos um grande sucesso quando utilizados em favor da aprendizagem. Portanto, são recursos didáticos que subsidiam um novo tipo de educação baseada nas tecnologias digitais.

Os jogos digitais podem ser uma forma divertida e eficaz para aprender os mais diversos conteúdos. Trata-se de um recurso 
surpreendente não apenas para a aprendizagem escolar, mas também para diversos tipos de treinamento institucional [38].

Ao pensarmos em novas estratégias de aprendizagem devemos considerar também o desenvolvimento de jogos por alunos e professores em sala de aula. $\mathrm{O}$ ato de desenvolver seu próprio jogo possibilita ao aluno adquirir habilidades computacionais e explorar conteúdos de maneira mais significativa. Segundo Nogueira e Galdino [39], instiga o aluno a participar cada vez mais da construção do seu conhecimento oferecendo a eles a oportunidade de serem elementos ativos no processo de aprendizagem.

Nesse contexto, a aprendizagem baseada em jogos pode ser conceituada como uma estratégia que utiliza o jogo como uma ferramenta para que os estudantes se engajem ao aprendizado enquanto jogam [40].

Sendo assim, os jogos possuem potencial educacional, são engajadores, permitem que os usuários façam testes em um ambiente artificial e despertam nos jogadores o esforço constante para serem melhores. Além disso, possuem a vantagem de permitir que os usuários executem ações em uma prática simulada [41].

No entanto, a ausência de ferramentas de alto nível e o suporte para professores e alunos para criar jogos são impeditivos para os que desejam adotar essa abordagem inovadora de aprendizagem [42].

\subsection{Game Design}

O processo de produção de um jogo inicia com a definição do seu conceito inicial (Game Design) e termina com a criação de uma versão final do jogo, sendo que várias etapas acontecem entre esses dois pontos. É na etapa de elaboração do game design que são definidas a ideia central do jogo, seu estilo, público alvo, narrativa, mecânica, personagens, cenários, objetivos, fases, níveis de dificuldade, sonorização, entre outros aspectos [43].

Game Design é o processo de criar o conteúdo e as regras de um jogo; é o processo de criar objetivos que o jogador sinta-se motivado a alcançar e regras que este siga como se estivesse tomando decisões significativas para atingir esses propósitos [44].

Para Adams e Rollings [45], Game Design é a essência de um jogo. É nele onde é definido como o jogo funciona e se descreve seus elementos. Geralmente é elaborado com a participação de diferentes profissionais da equipe que irá produzir o jogo para certo tipo de público de jogadores.

Durante o game design é produzido o Game Design Document (GDD) que deverá conter todas as definições, requisitos e regras do jogo. O GDD pode ser definido como "um documento que descreve as características" do game design "em detalhes" [46].

GDD é uma produção textual que serve de referência para todos os envolvidos no desenvolvimento do jogo, mantendo todos ligados aos mesmos objetivos [47]. Geralmente possui uma estrutura encadeada de diversos elementos do jogo: conceito do jogo; mecânicas de jogo; interfaces com usuário; elementos gráficos estáticos, animados e de vídeo; descrição de personagens; enredo e história; sons e música; detalhamento de levels (fases), entre outros elementos. Através destes elementos é possível descrever o que um jogo deve ter, no entanto, de acordo com o detalhamento este documento pode ter de dezenas a centenas de páginas [48].

Podemos compreender o game design como um processo complexo, que permite a visualização de todo o conjunto do trabalho a ser desenvolvido pela equipe de produção de jogos [49].

Em se tratando de jogos digitais educativos, o game design deve levar em conta também os aspectos pedagógicos, tais como: descrição dos conteúdos pedagógicos, definição dos objetivos de aprendizagem, como o aluno será avaliado, quais habilidades desenvolvidas, estilos de aprendizagem, entre outros.

Pensar em levar o processo de produção do game design de um jogo educativo para sala de aula é imaginar diferentes possibilidades de aprendizagem, já que envolve diversos conhecimentos que podem estar relacionados aos conteúdos curriculares. Outro aspecto importante é a participação do educador como um articulador e facilitador do desenvolvimento das atividades que estão envolvidas na produção de um jogo educativo. A assimilação das técnicas necessárias para essa produção é possível e necessária em tempos cada vez mais imersos em uma realidade tecnológica que permeia todas as áreas do conhecimento.

\subsection{Linguagem Natural Controlada}

Os avanços tecnológicos, sobretudo na área da computação, trouxe a preocupação de aproximar as linguagens computacionais das linguagens utilizadas na comunicação humana (linguagens naturais).

A linguagem natural é aquela que surge naturalmente no meio social e é através dela que os seres humanos se comunicam. As línguas faladas, escritas e de sinais são exemplos de linguagens naturais. Uma das características dessa linguagem é a ambiguidade, ou seja, uma única expressão pode ter significados diferentes em vários contextos [34]. Por esse motivo, computadores possuem uma grande dificuldade de processá-las.

As linguagens naturais controladas - LNC são um conjunto reduzido das linguagens naturais com o objetivo principal de diminuir sua ambiguidade e complexidade. Em geral, consistem em um conjunto de palavras e regras que definem como essas devem ser utilizadas para formar sentenças válidas de maneira que possa ser mais bem compreendida pelos dispositivos computacionais [35].

As LNC relacionam conceitos limitados em um contexto específico do conhecimento, ou seja, são constituídas especialmente para uma determinada área e assunto, como por exemplo a especificação de game design.

Devido ser considerada relativamente simples e reduzida, com proximidade à nossa linguagem natural, acreditamos que as LNC possam ser facilmente utilizadas na especificação de game design de jogos digitais por professores e alunos. 


\section{ESTRATÉGIA DE ESPECIFICAÇÃO DE GAME DESIGN DE JOGOS DIGITAIS}

A estratégia proposta neste trabalho tem por objetivo promover o desenvolvimento do pensamento computacional e habilidades de produção textual de alunos através da especificação do game design de jogos digitais. Basicamente é composta por 3 etapas principais, conforme ilustrado na Figura 1.

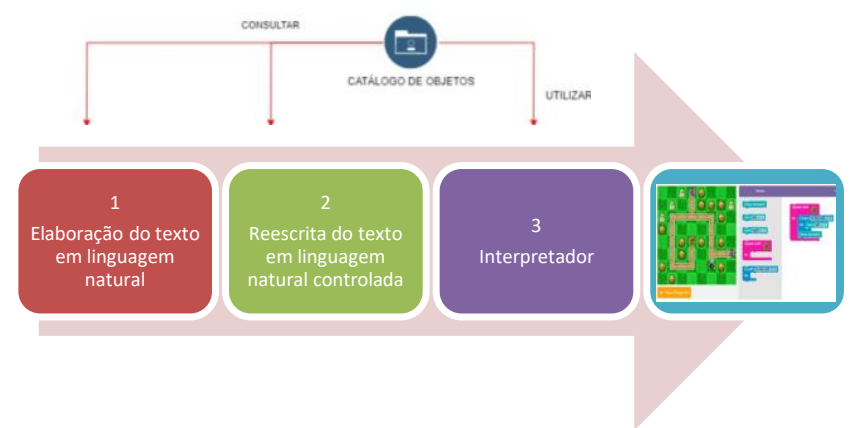

Figura 1. Visão geral da estratégia proposta.

Inicialmente os alunos produzirão um texto, em linguagem natural, representando a ideia do jogo (1). Acreditamos que nessa etapa os alunos terão a oportunidade de desenvolver a capacidade de expressar ideias com clareza e as habilidades de escrita de maneira lúdica e prazerosa. A idealização do seu próprio jogo pode configurar-se como um fator motivacional para a sua produção textual.

O texto deve apresentar a história, o cenário, os personagens, as regras e demais elementos do jogo. Esses são os elementos comuns presentes na maioria dos documentos de game design utilizados na indústria e na academia [20, 21, 22, 23, 24, 25, 26, 27].

Será utilizado um catálogo de objetos como forma de estimular a criatividade dos alunos. Esse catálogo contém imagens variadas de elementos que deverão compor o jogo (cenários, personagens, objetos). Esse tipo de catálogo já é utilizado em outras abordagens, como por exemplo, o Scratch Object Model [29].

Poderão ser utilizados os guias do professor e do aluno que contem orientações para produção de um jogo específico. Esses guias constituem um material orientativo com exemplos da produção de jogos específicos utilizando a estratégia proposta.

A etapa seguinte (2) consiste na reescrita do texto em linguagem natural controlada (LNC). Utilizaremos uma LNC para facilitar a interpretação do texto pelo computador, pois sabemos que o processamento de linguagem natural é ainda um grande desafio [28, 30, 31].

Acreditamos que a reescrita do texto em linguagem natural controlada possa favorecer o desenvolvimento do pensamento computacional dos alunos, já que é necessário dominar a linguagem para que o computador a interprete de maneira satisfatória. Seria como uma "linguagem de programação" bem próxima à nossa linguagem natural o que facilita a sua compreensão. O aluno tem a oportunidade de utilizar a linguagem, desenvolver o seu raciocínio lógico, elaborar uma problemática e uma solução de resolução desta através do jogo.

A próxima etapa (3) é a interpretação do texto e geração do jogo. Esse procedimento será feito por uma ferramenta que realizará o processamento do texto, digitado em LNC pelo aluno, gerando em seguida os artefatos componentes do game design do jogo especificados no texto. A partir desse momento, o aluno terá a disposição a interface do seu próprio jogo pronta para ser jogada em uma plataforma de execução como, por exemplo: o Scratch, Code.org e Blockly.

Para exemplificar essa etapa, imagine que o aluno digitou o seguinte texto: "O cenário é uma pista de corrida. O personagem é um carro de corrida. O piloto do carro é Airton Senna. O carro de corrida está na posição [20-23]."

O texto é interpretado pela ferramenta que gera a tela do jogo (Figura 2) com os seguintes elementos: Cenário = pista de corrida; Personagem $=$ carro de corrida; Carro de corrida = Airton Senna; Carro de corrida $=$ posição $[20-23]$.

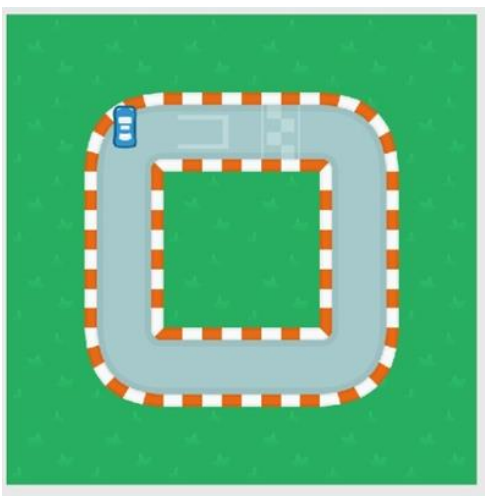

Figura 2. Resultado do processamento do texto.

A ferramenta executa a montagem do jogo buscando no catálogo de objetos a imagem da pista de corrida e um carro de corrida que é inserido na posição [20-23] da tela, como ilustrado na Figura 2.

A experiência aqui relatada concentra-se na etapa 1 da proposta, na utilização do catálogo e no guia do aluno, procurando compreender os requisitos necessários e a melhor maneira para realizar as etapas seguintes. É parte integrante da proposta de doutoramento de um dos autores deste trabalho.

\section{RELATO DA EXPERIÊNCIA DA PRODUÇÃO DE JOGOS}

Esta seção apresenta um estudo exploratório que buscou executar parcialmente a estratégia de especificação do game design de jogos digitais través da produção textual apresentada na seção anterior. $\mathrm{O}$ estudo buscou compreender os fenômenos observados durante a aplicação e resultados das atividades propostas [32-33]. Foi dividido em 3 etapas, conforme a Figura 3. 


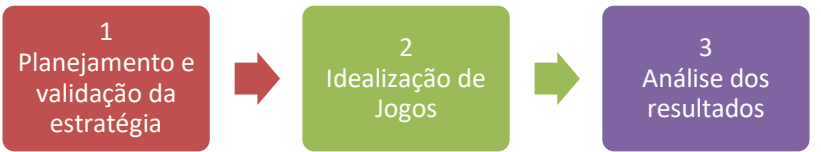

Figura 3. Etapas do Estudo Exploratório.

O público participante da experiência foi formado por professores, alunos e o pesquisador, assim divididos: na primeira etapa participaram 02 alunos do ensino fundamental (nível 4), 01 professora da educação básica, ambos de uma escola de aplicação de uma Universidade Brasileira), e 01 pesquisador; na segunda etapa participaram 20 alunos do ensino superior de uma Universidade Federal Brasileira (cursos de computação e pedagogia), 02 professores (educação básica e Computação) e 01 pesquisador; na ultima etapa participaram 02 professoras da educação básica da mesma escola de aplicação já citada anteriormente.

A seguir detalhamos o planejamento e a execução de cada etapa da experiência aqui relatada.

\subsection{Planejamento e Validação da Estratégia}

Nesta etapa foi realizado todo o planejamento da experiência detalhando o público alvo, materiais utilizados, estratégia de condução da experiência e avaliação dos resultados. Essa atividade foi realizada com a professora e o pesquisador participantes. Em seguida, partimos para a execução do planejamento com os alunos selecionados para essa etapa com o objetivo de testarmos e validarmos a estratégia planejada.

A atividade proposta foi a elaboração do game design de um jogo através da produção textual. Primeiramente, a professora explicou o objetivo da atividade, falou sobre o conceito de jogos digitais e game design mostrando aos participantes quais elementos são indispensáveis para elaboração de um jogo, tais como: história, personagens, cenário, regras, entre outros. Demonstrou ainda um catálogo de objetos dispostos na forma de cartões impressos contendo imagens de personagens, objetos, ações e cenários que deveriam ser utilizados na elaboração do game design dos jogos idealizados. Os alunos conheceram e manipularam os cartões como forma de inspiração para estruturação da ideia e os elementos do jogo, conforme ilustrado na Figura 4.

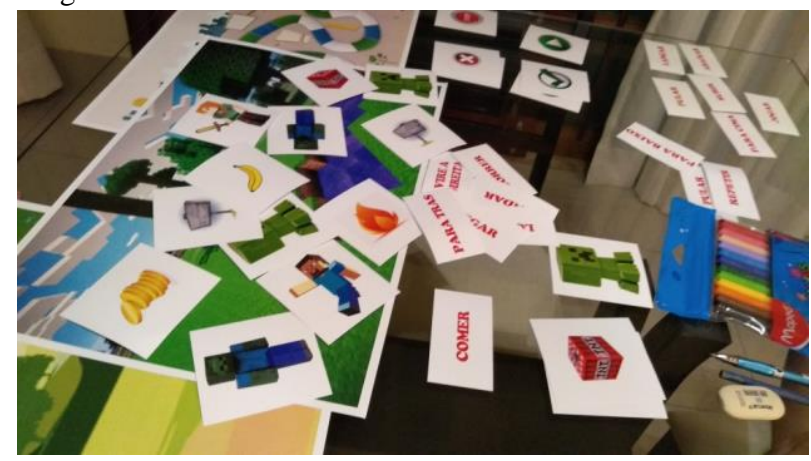

Figura 4. Conhecendo o catálogo de objetos.
Os alunos socializaram oralmente a ideia do jogo, na medida em que manipulavam os cartões sob o cenário escolhido, explicitando onde ele se passaria, quais personagens apareciam, quais seriam as suas ações e quais seriam as tarefas/desafios que deveriam ser superados. Em seguida fizeram o registro escrito do jogo, considerando o que estava estruturado sob a mesa, conforme Figura 5 .

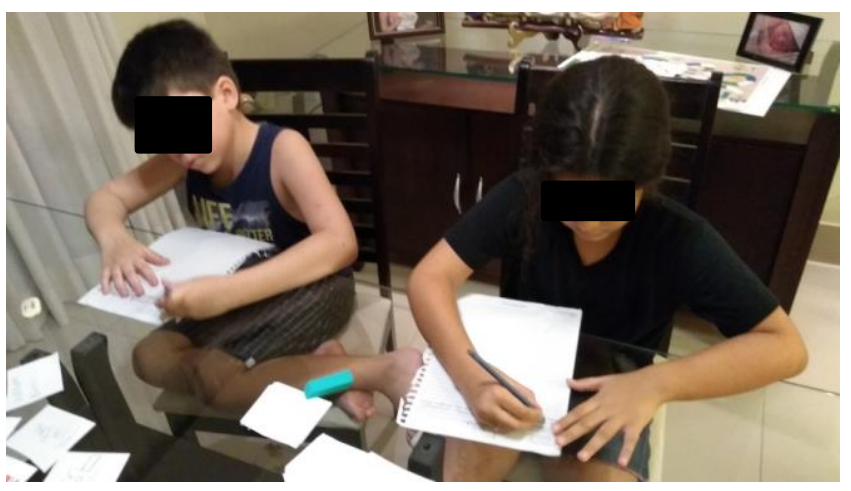

Figura 5. Produção textual.

O texto foi revisto em vários momentos com o objetivo de favorecer a clareza do registro quanto ao funcionamento do jogo e adequar a escrita à norma culta. Essa etapa contou com a ajuda da professora que orientou sobre a escrita correta do texto produzido. Com o texto concluído, os alunos identificaram os elementos do game design do jogo idealizado simulando o papel do interpretador (Etapa 3 da figura 1). Ao perceberem a falta de algum elemento, voltavam ao texto para fazerem os ajustes necessários. Ao final da atividade os alunos foram entrevistados pelo pesquisador com o objetivo de perceber se os mesmos sentiram dificuldades ao descrever os elementos do jogo, se sentiram motivados a produzir o texto e se consideram que a descrição do jogo através do texto pode se transformar num jogo real.

A etapa de planejamento e validação da estratégia teve a duração de 3 semanas.

\subsection{Idealização de Jogos}

Após validada a estratégia, partimos para a execução com o segundo grupo de participantes. Dessa vez, a atividade foi realizada na forma de oficina (com duração de 4 horas) realizada num encontro científico de uma Universidade Federal Brasileira.

Da mesma forma, os alunos foram apresentados a proposta, conheceram os conceitos de jogos digitais, game design e o catálogo de objetos. Em seguida, os 20 alunos foram divididos em 5 grupos. Cada grupo recebeu um kit contendo o catálogo de objetos, papel e canetas. Os alunos manipularam o material disponibilizado, idealizaram seus jogos, socializaram a ideia internamente no grupo e iniciaram o registro na forma de texto, conforme ilustrado nas Figuras 6 e 7. 


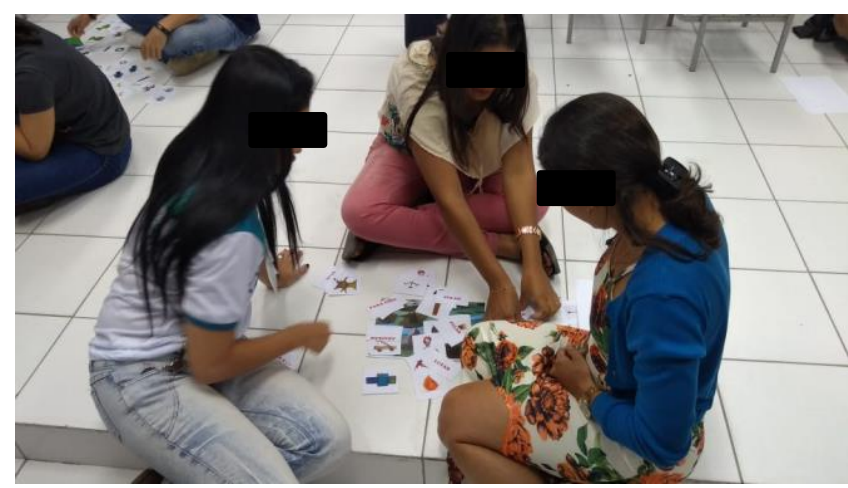

Figura 6. Idealizando o jogo.

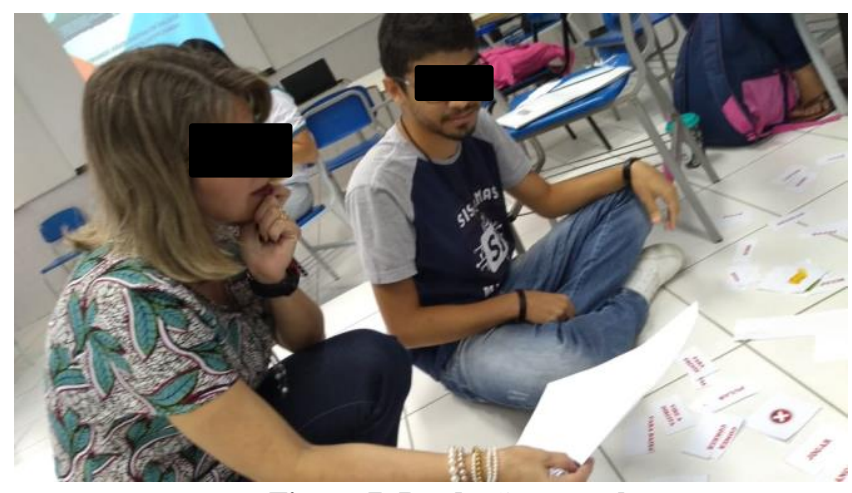

Figura 7. Produção textual.

Nessa experiência foram disponibilizados cartões em branco para a necessidade de expansão do catálogo de objetos. Cada grupo elaborou 01 jogo.

Após conclusão da ideia e elaboração do texto, os grupos socializaram oralmente com o grande grupo a medida que demonstravam a execução o jogo através da manipulação dos elementos selecionados no catálogo.

Finalmente, responderam a um pequeno questionário contendo as mesmas perguntas descritas na etapa de planejamento e validação da estratégia.

\subsection{Análise dos Resultados}

A terceira e última etapa foi a análise dos resultados. Foram considerados os jogos idealizados, a produção textual e a estratégia proposta. Os resultados são descritos a seguir.

\subsubsection{Considerações a Respeito dos Jogos Idealizados:}

Em relação aos jogos idealizados percebemos que não há limite para imaginação dos participantes. Verificamos o quanto os alunos são familiarizados com jogos digitais facilitando a elaboração da ideia dos jogos com a identificação de personagens, cenários, regras, mudança de níveis, pontuação e superação de desafios. Os alunos tiveram a oportunidade de fazer uso da sua experiência como usuários de jogos, para propor jogos que eles mesmos tinham interesse em jogar.
Num primeiro momento verificamos que a quantidade de elementos do catálogo de objetos constitui-se como um fator limitante para elaboração dos jogos, porém na $2^{\mathrm{a}}$ etapa foi dada a oportunidade dos alunos expandirem o catálogo elaborando novos elementos nos cartões em branco.

\subsubsection{Considerações a Respeito da Produção Textual}

$\mathrm{O}$ registro por escrito da descrição dos elementos e funcionamento dos jogos se constituiu em uma atividade essencial para que os alunos pudessem sistematizar as suas ideias e melhor estruturar seus jogos. Elas colocaram em prática as suas habilidades de escrita, motivadas pelo interesse de criação de um produto digital.

Revisitar o texto verificando sua completude e escrita correta deu a oportunidade ao alunos de conhecerem e aprimorarem os conhecimentos relacionados a produção textual e forma significativa e lúdica.

Essa produção textual pode ser considerada como um documento de game design (GDD) elaborado sem tanta complexidade e formalidade como os GDD tradicionais e sem requerer habilidades muito técnicas da área de computação, já que é utilizada a nossa linguagem natural.

Observamos que os textos produzidos durante a experiência são curtos e incompletos. Isso talvez em decorrência do pouco tempo destinado a elaboração dos mesmos.

Mesmo estando incompletos foi possível observar a existência da descrição dos principais elementos do game design. Todos conseguiram descrever os cenários e personagens dos jogos. Algumas regras foram também apresentadas. Assim, acreditamos ser possível extrair características principais do game design, porém a incompletude dos textos dificulta essa atividade.

\subsubsection{Considerações a Respeito da Estratégia Proposta}

Após realizada a experiência aqui relatada, pudemos constatar que a estratégia de criação de jogos a partir da linguagem natural de fato é uma alternativa para adoção da aprendizagem baseada em jogos, desenvolvimento do pensamento computacional e das habilidades de escrita.

As habilidades do pensamento computacional são trabalhadas no momento em que os alunos pensam na problemática do jogo, sua decomposição, nos algoritmos com as regras, mudança de fases e superação de desafios.

Favorece as habilidades da língua portuguesa, especificamente da produção textual a medida que usam a leitura e escrita para elaboração do game design dos jogos. A estratégia proposta constitui-se como uma atividade prática, motivadora, lúdica e significativa para o desenvolvimento dessas habilidades.

Através dos questionamentos realizados no final de cada etapa constatamos que a maioria dos alunos não sentiram dificuldades ao descrever os elementos do jogo e se sentiram bastante motivados a produzir o texto. Porém, nem todos concordaram que seu texto pode se transformar num jogo real em razão do pouco tempo destinado a sua produção. 


\section{CONCLUSÕES}

Várias pesquisas têm evidenciado experiências positivas da aprendizagem baseada em jogos. No entanto, poucas são as estratégias de desenvolvimento de jogos por não especialistas.

A proposta aqui apresentada encapsula os aspectos técnicos do design de jogos tornando o processo de desenvolvimento mais natural para professores e alunos em sala de aula, contribuindo para a adoção da aprendizagem baseada em jogos.

Esta solução pode colaborar para que os alunos adquiram os conhecimentos necessários para o desenvolvimento das habilidades de tecnologia e da computação necessárias para a formação do pensamento computacional, bem como habilidades de leitura e escrita em linguagem natural.

\section{AGRADECIMENTOS}

Essa pesquisa é financiada em parte pela Coordenação de Aperfeiçoamento de Pessoal de Nível Superior - Brasil (CAPES) Código 001.

\section{REFERÊNCIAS}

[1] Allan, V. et al. (2010) Computational thinking in high school courses". In: Proceedings of the 41st SIGCSE, p. 390-391.

[2] Barcelos, T. S., Silveira, I. F. (2012). Teaching Computational Thinking in initial series An analysis of the confluence among mathematics and Computer Sciences in elementary education and its implications for higher education. p.1-8, IEEE.

[3] Barcelos,T.; Muñoz, R.; Villarroel R.; Silveira, I. (2015). Relações entre o Pensamento Computacional e a Matemática: uma Revisão Sistemática da Literatura. Anais dos Workshops do Congresso Brasileiro de Informática na Educação.

[4] Brasil, Base Nacional Comum Curricular, Ministério da Educação - MEC, http://basenacionalcomum.mec.gov.br

[5] CIEB, Currículo de referência em Tecnologia e Computação, Centro de Inovação para a Educação Brasileira, http://curriculo.cieb.net.br.

[6] Danielle, N. Gomes, Araújo, Luiz, Machado, Thiago, Filho, Angelo, Souza, Silvana. (2015). Ensino Aprendizagem Através de Desenvolvimento de Jogos. In: Simpósio Brasileiro de Jogos - SBGames.

[7] e-UCM research group (Complutense University of Madrid), eAdventure, http://e-adven ture.e-ucm.es/

[8] Fernandes, Kleber; Aranha, Eduardo; Lucena, Márcia (2018). Estratégias para Elaboração de Game Design de Jogos Digitais Educativos: uma Revisão Sistemática. In: XXIX Simpósio Brasileiro de Informática na Educação (Brazilian Symposium on Computers in Education), Fortaleza, p. 585.

[9] Kordaki, M., Diverse categories of programming learning activities could be performed within scratch. In: 4th World Conference Alice Team: Alice. http://www.alice .org/

[10] Lifelong Kindergarten, Scratch, https ://scrat ch.mit.edu/

[11] Marinho, F. C. V., Giannella, T. R. and Struchiner, M. (2011). Estudantes do Ensino Básico Como Desenvolvedores de Jogos Digitais: Contextos Autênticos de Aprendizagem para Educação em Ciências e Matemática. In: VIII Encontro
Nacional de Pesquisa em Educação em Ciências, Campinas, São Paulo.

[12] Moshirnia, A. (2007). The educational potential of modified video games.Issues Inf. Sci. Inf. Technol. 4, 511-521.

[13] OCDE, Programme for International Student Assessment PISA, Organisation for Economic Co-operation and Development, http://www.oecd.org/pisa/.

[14] Ozcelik, E., Cagiltay, N.E., Ozcelik, N.S. (2013). The effect of uncertaintyon learning in game-like environments. Comput. Educ. 67, 12-20. https ://doi.org/10.1016/j.compe du.2013.02.009

[15] Schmitz, B., Czauderna, A., Klemke, R. and Specht, M. (2011). Game based learning for computer science education, Proceedings of Computer Science Education Research Conference, Heerlen, The Netherlands, pp.81-88.

[16] Torrente, J., Blanco, Á., Marchiori, E.J., Moreno-ger, P., Fernández-Manjón, B., Del Blanco, Á. (2010). Introducing educational gamesin the learning process. IEEE Education Engineering EDUCON 2010 Conference, vol. 127, pp. 1121-1126. https ://doi.org/10.1109/educo n.2010.54930 56

[17] Yuan, B., Folmer, E., Harris, F.C. (2011). Game accessibility: a survey. Univ. Access Inf. Soc. 10, 81-100 https ://doi.org/10.1007/s1020 9-010-0189-5

[18] Johnsgard, K., McDonald, J.: Using alice in overview courses. http://www.alice .org/

[19] Code.org, A hora do código, http://code.org

[20] Hira, Willian; Marinho, Marcos; Pereira, Felipe; Barboza, Alcides (2016). Criação de um modelo conceitual para documentação de game design, in Simpósio Brasileiro de Games - SBGAMES.

[21] Mariasch, Steven; Silva, Luciano(2017). Análise de modelos de documentos de game design e proposta de padrão unificado in Simpósio Brasileiro de Jogos - SBGAMES.

[22] Cezarotto, Matheus Araujo; Battaiola, André Luiz (2017). Estudo comparativo entre modelos degame design para jogos educacionais, in Simpósio Brasileiro de Jogos - SBGAMES.

[23] Leite, Patricia da Silva; Mendonça, Vinícius Godoy (2013). Diretrizes para Game Design de Jogos Educacionais in Simpósio Brasileiro de Jogos - SBGAMES.

[24] Motta, Rodrigo L.; Junior, José Trigueiro (2013). Short game design document (SGDD)Documento de game design aplicado a jogos de pequeno porte e advergames: Um estudo de caso do advergame Rockergirl Bikeway. in Simpósio Brasileiro de Jogos - SBGAMES.

[25] Sarinho, Victor Travassos (2017). Uma Proposta de Game Design Canvas Unificado in Simpósio Brasileiro de Jogos SBGAMES.

[26] Mishra, Punya; Koehler, Matthew J. “(2006). Technological Pedagogical Content Knowledge: A Framework for Teacher Knowledge in Teachers College Record 108:1017-105.

[27] Winn, Brian M. (2009). The Design, Play, and Experience Framework In book: Handbook of Research on Effective Electronic Gaming in Education, pp.1010-1024.

[28] Vieira, Renata; Lopes, Lucelene (2010). Processamento de Linguagem Natural e o Tratamento Computacional de Linguagens Científicas. Linguagens Especializadas em Corpora. EdiPUCRS. 
[29] Maloney, J.; Resnick M.;Rusk N.;Silverman B.;Eastmond E. (2010). The Scratch Programming Language and Environment. ACM Trans. Comput. Educ. 10, 4, Article 16 (November 2010), 15 pages. DOI = $10.1145 / 1868358.1868363$. http://doi.acm.org/10.1145/1868358.1868363.

[30] Liddy, E. D.(2003). Natural Language Processing. In: Encyclopedia of Library and Information Science, 2nd ed.

[31] Ladeira, Lidia. Processamento de linguagem natural: caracterizacao da produção científica dos pesquisadores brasileiros. Tese de doutorado. Biblioteca Digital da UFMG. Disponível em http://hdl.handle.net/1843/ECID-8B3Q6C.

[32] Wohlin, C. (2012). Experimentation in Software Engineering. Springer Verlag.

[33] Yin, R. K.(2013). Case Study Research: Design and Methods. SAGE Publications, Inc; 5. Edição.

[34] Lancaster, F. W (2003). Indexação e resumos: teoria e prática. Brasília. Briquet de Lemos.

[35] Kuhn, T. e Schwitter, R. (2008). Writing Support for Controlled Natural Languages. In: Powers, D., Stockes, N. (eds.) Proceedings of ALTA, pp. 46-54. Conference Name:ACM Woodstock conference

[36] Wing, J. (2006). Computacional Thinking. In: Communications of the ACM. 49, New York, p. 33-35.

[37] Brackmann, Christian (2017). Desenvolvimento do Pensamento Computacional Através de Atividades Desplugadas na Educação Básica. Universidade Federal do Rio Grande do Sul (UFRGS), Porto Alegre, RS, Brasil.

[38] Prensky, Marc (2012). Aprendizagem baseada em jogos digitais. São Paulo: Editora Senac, São Paulo.

[39] Nogueira, A. S.; Galdino, A. L.(2012). Games como agentes motivadores na educação. In: VIII Seminário Jogos eletrônicos, Educação e Comunicação. Salvador/BA.

[40] Sidhu, M. S. (2010). Technology-assisted problem solving for engineering education: interactive multimedia applications. Hershey: Engineering Science Reference.

[41] Shaffer, David Williamson (2006) How Computer Games Help Children Learn. New York; Palgrave MacMillian.

[42] Tang, S. and M. Hanneghan (2011). State-of-the-Art Model Driven Game Development: A Survey of Technological Solutions for Game-Based Learning, Journal of Interactive Learning Research.

[43] Chandler, H. M. (2012). Manual de Produção de Jogos Digitais. Porto Alegre - RS: Bookman.

[44] Brathwaite, Brenda; Schreiber, Iran (2009). Challenges for Game Designers: non-digital exercicies for vídeo game designers. Boston: Cengage Leaning.

[45] Adams, Ernest; Rpllings, Andrew. (2007) Fundamental of Game Design. New Jersey: Pearson Prentice Hall.

[46] Perucia , A. S., A. C. Berthêm, G. L. Bertschinger e R. R. C. Menezes (2005). Desenvolvimento de Jogos Eletrônicos: teoria e prática. São Paulo: Novatec Editora.

[47] Pedersen, R. (2003) Game design foundations. 1.ED. Sudbury: Wordware publishing.

[48] Ryan, T. (2011) Learning the Ways of the Game Development Wiki. http://w w w. ga m a s u tra.com/v i e w / feature/4094/learning_the_ways_of_the_game_.php? page $=$.
[49] Arruda, Eucidio Pimenta (2014). Fundamentos para o desenvolvimento de jogos digitais. Porto Alegre: Bookman. 